\title{
Evaluation of a simplified oscillation technique for assessing airway obstruction in sleep apnoea
}

\author{
R. Farré*, J. Rigau*, J.M. Montserrat*, E. Ballester\#, D. Navajas*
}

Evaluation of a simplified oscillation technique for assessing airway obstruction in sleep apnoea. R. Farré, J. Rigau, J.M. Montserrat, E. Ballester, D. Navajas. (C)ER Journals Ltd 2001.

ABSTRACT: The forced oscillation technique (FOT) is a noninvasive method that is useful for assessing airway obstruction and for titrating continuous positive airway pressure (CPAP) in patients with sleep apnoea. The aim was to evaluate the routine applicability of a simplified FOT set-up based on recording pressure and flow at the level of the CPAP device, i.e. obviating the need for connecting the transducers to the nasal mask.

A correction to account for the tubing and the exhaust port was applied. This simplified FOT was evaluated on nine patients with moderate or severe sleep apnoea during routine CPAP titration. Patient impedance measured by the simplified FOT (|Z|) was compared with actual patient impedance $\left(\left|Z_{\mathrm{rs}}\right|\right)$ measured simultaneously with a reference FOT based on recording pressure and flow at the nasal mask.

An excellent agreement was found between $|Z|$ and $\left|Z_{\mathrm{rs}}\right|$ over the wide range of airway obstruction explored $\left(4.8-72.1 \mathrm{cmH}_{2} \mathrm{O} \cdot \mathrm{s} \cdot \mathrm{L}^{-1}\right):|Z|=|Z \mathrm{rs}| \times 0.86+1.3 \mathrm{cmH}_{2} \mathrm{O} \cdot \mathrm{s} \cdot \mathrm{L}^{-1}(\mathrm{r}=$ 0.99). Moreover, the simplified and the conventional FOT settings detected the same respiratory events during sleep.

These results demonstrate that this simplified FOT is applicable for measuring airway obstruction during routine sleep studies in patients with sleep apnoea.

Eur Respir J 2001; 17: 456-461.
*Unitat de Biofisica i Bioenginyeria, Facultat de Medicina, Universitat de Barcelona and ${ }^{\#}$ Institut de Pneumologia i Cirurgia Toràcica, Hospital Clinic. Institut $\mathrm{d}^{\prime}$ Investigacions Biomèdiques August Pi Sunyer, Barcelona, Spain.

Correspondence: R. Farré, Unitat Biofisica i Bioenginyeria, Facultat Medicina, Casanova 143, 08036 Barcelona, Spain.

Fax: 34934024516

Keywords: Airway resistance, respiratory impedance, sleep monitoring

Received: June 152000

Accepted after revision October 102000

This work was supported in part by Comision Interministerial de Ciencia y Tecnologia (CICYT, SAF99-0001) and by Direccion General de Enseñanza Superior e Investigacion Cientifica (DGESIC, PM98-0027).
The sleep apnoea/hypopnoea syndrome (SAHS) is characterized by recurrent elevation of airflow obstruction due to total or partial collapse in the upper airway. The forced oscillation technique (FOT) is a noninvasive method particularly suitable for assessing airway impedance during application of nasal continuous positive airway pressure (CPAP) [1] and, in particular, during the apnoeas and hypopnoeas in patients with SAHS during sleep $[2,3]$. Recent studies have demonstrated that FOT may be a helpful tool for the diagnosis of SAHS [4] and for the titration of the level of CPAP to treat the patient [5-7].

Widespread routine application of this technique in the clinical arena would be facilitated by simplifying the conventional FOT set-up used in previous studies. One possible simplification of the method, which could improve patient comfort and clinical applicability, consists in recording pressure and flow at the inlet of the tubing connecting the CPAP device and the nasal mask. This procedure would avoid the connection of the pneumotachograph and pressure transducers to the nasal mask, which is the conventional setting [1-6]. With such a simplified FOT the impedance actually measured would not be actual patient impedance but the combination of patient impedance with the impedances of the tubing and the effective impedance of the nonlinear exhaust port. Nevertheless, airway obstruction could be adequately estimated by correcting the measured impedance for the artefacts induced by the tubing and the exhaust port, as recently shown in a calibration study on mechanical analogues [8]. The aim of the present work was to determine whether this simplified FOT approach is easily applicable and reliable for measuring airway obstruction in routine sleep studies. To this end, the simplified FOT was evaluated when routinely applied in nine patients with SAHS during sleep. The results obtained with this simplified FOT approach were compared with those simultaneously obtained with a reference FOT setting based on recording pressure and flow at the nasal mask.

\section{Methods}

\section{Patients}

The study was carried out on nine patients with a diagnosis of moderate or severe SAHS documented by polysomnography. The patients had not been previously treated with CPAP (4 female $/ 5$ male, age $=60 \pm$ $10 \mathrm{yr}$, body mass index $=34 \pm 4 \mathrm{~kg} \cdot \mathrm{m}^{-2}$, apnoea/hypopnoea index $=45 \pm 26$ per hour, Epworth $=12 \pm 5$; mean \pm SD). The protocol was approved by the Human Ethics Committee of the authors' Hospital and informed written consent was obtained from all patients. 


\section{FOT set-up}

Figure 1 is a diagram of the set-up used to evaluate the clinical application of the simplified FOT during routine sleep studies. Forced oscillation pressure $(5 \mathrm{~Hz}$, $\pm 1 \mathrm{cmH}_{2} \mathrm{O}$ ) was generated by means of a loudspeakerin-box (JBL-800GTI, 8-in subwoofer, $600 \mathrm{~W}$; JBL, Vitoria, Spain) connected in parallel with a conventional CPAP device (CP90-Taema, Airliquide, Antony Cedex, France). The rear part of the loudspeaker was enclosed in a $2 \mathrm{~L}$ chamber to allow the loudspeaker cone to withstand positive pressure generated by the CPAP device. CPAP and FOT were simultaneously applied to the patient through a conventional flexible tubing (175 $\mathrm{cm}$ in length and $2 \mathrm{~cm}$ internal diameter), a whisper swivel exhaust port (Respironics Inc, Murrysville, PA, USA) and a nasal mask. Pressure $(P)$ and flow $\left(V^{\prime}\right)$ were recorded by sensors placed at the inlet of the tubing (fig. 1). $P$ was measured with a pressure transducer (MP-45, Validyne, Northridge, CA, USA) and $V^{\prime}$ was measured with a Fleisch-II pneumotachograph (Sibel, Barcelona, Spain) plus differential pressure transducer (MP-45, Validyne, Northridge, CA, USA). Both signals were low-pass filtered (Butterworth, 8 poles, $32 \mathrm{~Hz}$ ), sampled at $100 \mathrm{~Hz}$ (CODAS, DATAQ Instruments Inc, Akron, OH, USA) and stored in a microcomputer.

\section{Calibration}

According to a previous calibration study [8], the setup parameters to compute patient impedance were determined from recorded $P$ and $V^{\prime}$ (fig. 1). First, the compliance of the tubing $(C \mathrm{~T})$ was determined by occluding both sides, injecting a small volume of air $(\Delta V=5 \mathrm{~mL})$ with a conventional syringe and measuring the resulting pressure increase $\Delta P(C \mathrm{~T}=\Delta V / \Delta P=0.59$ $\left.\mathrm{mL} \cdot \mathrm{cmH}_{2} \mathrm{O}^{-1}\right)$. $C$ T included the compliance of enclosed air and that of the nonrigid wall. Second, the resistive properties of the exhaust port, which are described by a nonlinear $P-V^{\prime}$ relationship $\left(P=\mathrm{K} 1 V^{\prime}+\mathrm{K} 2 V^{\prime 2}\right)$, were determined by measuring $P$ and $V^{\prime}$ (fig. 1) when the nasal mask was occluded, for $\mathrm{CPAP}=5$ and $15 \mathrm{cmH}_{2} \mathrm{O}$. From this two-point calibration the values $\mathrm{K}_{1}=7.0$

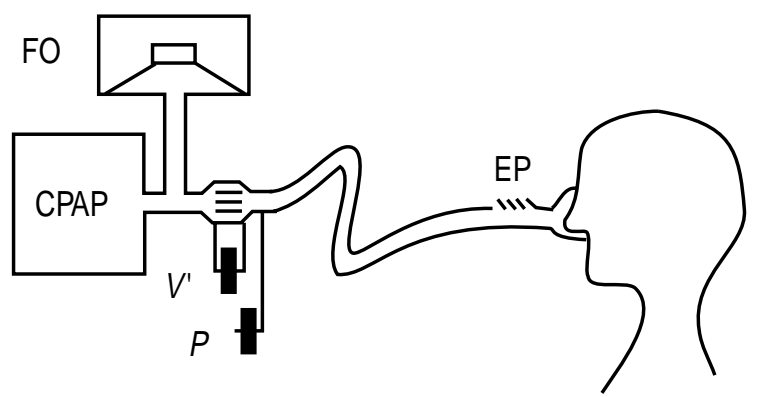

Fig. 1. - Schematic diagram of the simplified forced oscillation set-up. CPAP: continuous positive airway pressure device; FO: forced oscillation generator; EP: exhaust port. $P$ and $V^{\prime}$ : measured pressure and flow. To evaluate the simplified method, actual nasal pressure and flow were also measured by placing similar transducers between the exhaust port and the nasal mask (see text for explanation).
$\mathrm{cmH}_{2} \mathrm{O} \cdot \mathrm{s} \cdot \mathrm{L}^{-1}$ and $\mathrm{K}_{2}=83.7 \mathrm{cmH}_{2} \mathrm{O} \cdot \mathrm{s}^{-2} \cdot \mathrm{L}^{2}$ were derived characterizing the exhaust port used.

\section{Estimation of nasal flow and flow through the exhaust port}

The calibration constants accounting for the effective resistance of the exhaust port ( $\mathrm{K}_{1}$ and $\left.\mathrm{K}_{2}\right)$ were used to estimate actual breathing flow at the nose from $V^{\prime}$ measured with the pneumotachograph placed at the inlet of the tubing in the simplified FOT set-up (fig. 1). The procedure was based on the fact that actual nasal flow is the difference between measured flow $V^{\prime}$ and airflow through the exhaust port, which can be estimated from $\mathrm{K} 1$ and $\mathrm{K} 2$ and the value of pressure at the exhaust port. First, the pressure at the exhaust port was estimated as measured $P$ minus the small pressure drop due to the measured flow $V^{\prime}$ across the low resistance $\left(0.5 \mathrm{cmH}_{2} \mathrm{O} \cdot \mathrm{s} \cdot \mathrm{L}^{-1}\right)$ of the tubing. Given the low frequency band of the breathing signals, no correction was applied for $C \mathrm{~T}$ when estimating the almost constant flow through the exhaust port (the shunt impedance due to $C$ T at a breathing frequency of $0.25 \mathrm{~Hz}$ is $\sim 1,000$ $\left.\mathrm{cmH}_{2} \mathrm{O} \cdot \mathrm{s} \cdot \mathrm{L}^{-1}\right)$. Second, the flow through the exhaust port was estimated by solving the nonlinear equation describing the pressure-flow relationship in the exhaust port $\left(\mathrm{P}=\mathrm{K} 1 \cdot V^{\prime}+\mathrm{K}_{2} \cdot V^{\prime 2}\right)$. Finally, nasal flow was estimated as measured $V^{\prime}$ minus the flow through the exhaust port.

\section{Impedance computation}

The time course of estimated patient impedance $(Z)$ was determined by frequency analysis of recorded $P$ and $V^{\prime}$ [2] and by subsequently correcting for the tubing and exhaust port [8]. Briefly, a moving average filter ( $0.2 \mathrm{~s}$ centred window) was applied to $P$ and $V^{\prime}$ to separate the $5 \mathrm{~Hz}$ FOT components and the lowfrequency signal components due to CPAP and spontaneous breathing. The $5 \mathrm{~Hz}$ FOT component was obtained by subtracting the filtered signals from the raw signals. Impedance was computed every $0.01 \mathrm{~s}$ by means of a cycle-by-cycle $(0.2 \mathrm{~s})$ Fourier analysis of the pressure and flow oscillatory components and smoothed with a moving average filter (centred window of $0.4 \mathrm{~s}$ including 40 impedance estimates). Computed impedance was first corrected for the compliance of the tubing and subsequently for the effective resistance of the exhaust port. To this end the calibration parameters of the set-up $\left(C T, \mathrm{~K}_{1}, \mathrm{~K}_{2}\right)$ were used as described in detail in [8]. Finally, the amplitude $(|Z|)$ of estimated impedance $Z$ was computed.

\section{Comparison with actual patient impedance}

Patient impedance estimated with the simplified FOT $(Z)$ was compared with actual patient impedance $(Z \mathrm{rs})$ measured simultaneously by a reference FOT, which was based on recording actual nasal pressure and flow at the mask [1]. To this end, a pneumotachograph and pressure transducers similar to those in the simplified FOT set-up were connected at the inlet of the mask. To 
compute the amplitude of $Z_{\mathrm{rs}}\left(\left|Z_{\mathrm{rs}}\right|\right)$ pressure and flow signals recorded at the nasal mask were subjected to the same sampling and processing as that described to compute $|Z|$ from $P$ and $V^{\prime}$, with the exception of the correction for the tubing and exhaust port.

\section{Protocol}

The patient study was carried out during a nap of at least $2 \mathrm{~h}$ of stable sleep. Complete polysomnography was performed in a conventional manner with continuous recording of the electroencephalogram (O4/A1, C3/A2, Z1/A2), chin electromyogram and electroculogram. Oxygen saturation was measured with a finger probe pulse oximeter (504, Critical Care Systems Inc, Waukesha, WI, USA). Ribcage and abdominal movements were monitored by bands placed over the thorax and abdomen. All these signals were recorded on a polygraph (SleepLab 1000P, Aequitron, Minneapolis, MN, USA). The study started with the CPAP adjusted to a base line of $4 \mathrm{cmH}_{2} \mathrm{O}$ and the patient was allowed to sleep in the position she/he preferred. After achieving a stable non-REM sleep, a sleep lab technician initiated a stepwise increase in CPAP (steps of $1 \mathrm{cmH}_{2} \mathrm{O}$ every $5 \mathrm{~min}$ ) from base line level to optimal CPAP. This value was determined in accordance with the commonly used criteria of absence of apnoeas, hypopnoeas, periods of flow limitation and sleep fragmentation. $|Z \mathrm{rs}|$ and $|Z|$ were simultaneously measured throughout the sleep study.

\section{Impedance data analysis}

Evaluation of the performance of the simplified FOT in routine application was carried out in two steps. The first one was addressed to compare the values of $|Z|$ measured by the simplified FOT with the reference values of actual patient impedance $\left|Z_{\mathrm{rs}}\right|$ measured at the nasal mask. To perform this analysis over the widest impedance range possible, the lowest and highest values of $\left|Z_{\mathrm{rs}}\right|$ (minimal and maximal airway obstruction) observed for each patient and CPAP value were selected. Comparison between $|Z \mathrm{rs}|$ and the corresponding values of $|Z|$ was carried out by linear correlation analysis. The second step in the data analysis was addressed to evaluate the performance of the simplified FOT in detecting the apnoeas, hypopnoeas and periods of flow limitation characterizing SAHS. To this end, for each patient a section of the recording $(\sim 20 \mathrm{~min})$ was selected including a significant number $(>15)$ of respiratory events. From the FOT viewpoint, an obstructive respiratory event was scored in case of persistent or intermittent increase in impedance lasting $>10 \mathrm{~s}$ [5]. First, respiratory events were scored independently and in a blind mode by using signals $|Z|$ and $|Z \mathrm{rs}|$. Second, the three signals $V^{\prime},|Z|$ and $|Z \mathrm{rs}|$ were displayed simultaneously to evaluate the concordance and performance of the simplified and the reference FOT settings for detecting respiratory events on an event-by-event basis.

\section{Results}

The degree of airway obstruction detected by the simplified FOT $(|Z|)$ during its routine application was very close to actual airway obstruction $(|Z \mathrm{rs}|)$, as illustrated by three examples of respiratory events (fig. 2-5). Figure 2 shows the increases in $|Z|$ and $|Z \mathrm{rs}|$ during two obstructive apnoeas. Figure 3 illustrates an obstructive hypopnoea (recurrent increases in inspiratory $|Z|$ and $|Z \mathrm{rs}|)$ followed by normal breathing due to arousal (normalized low $|Z|$ and $|Z \mathrm{rs}|$ ). Figure 4 shows the recurrent increases in expiratory $|Z|$ and $\mid Z$ rs $\mid$ observed in an example of mouth expiration (indicated by positive inspiratory and zero expiratory flow) followed by nasal expiration.

Figure 5 shows the results obtained when comparing $|Z|$ and $\mid Z$ rs $\mid$ at the lowest and highest degrees of airway obstruction in all the patients and CPAP values. The simplified FOT slightly underestimated actual impedance: $|Z|=|Z \mathrm{rs}| \times 0.86+1.3 \mathrm{cmH}_{2} \mathrm{O} \cdot \mathrm{s} \cdot \mathrm{L}^{-1}$. The coefficient of linear correlation between these two variables over the wide range of airway obstruction explored (4.8-72.1 $\mathrm{cmH}_{2} \mathrm{O} \cdot \mathrm{s} \cdot \mathrm{L}^{-1}$ ) was excellent: $\mathrm{r}=0.99$. To assess the agreement between $|Z|$ and $|Z \mathrm{rs}|$, figure 5 shows the difference between these two values as a function of actual impedance. The difference between estimated and actual impedance showed a significantly negative

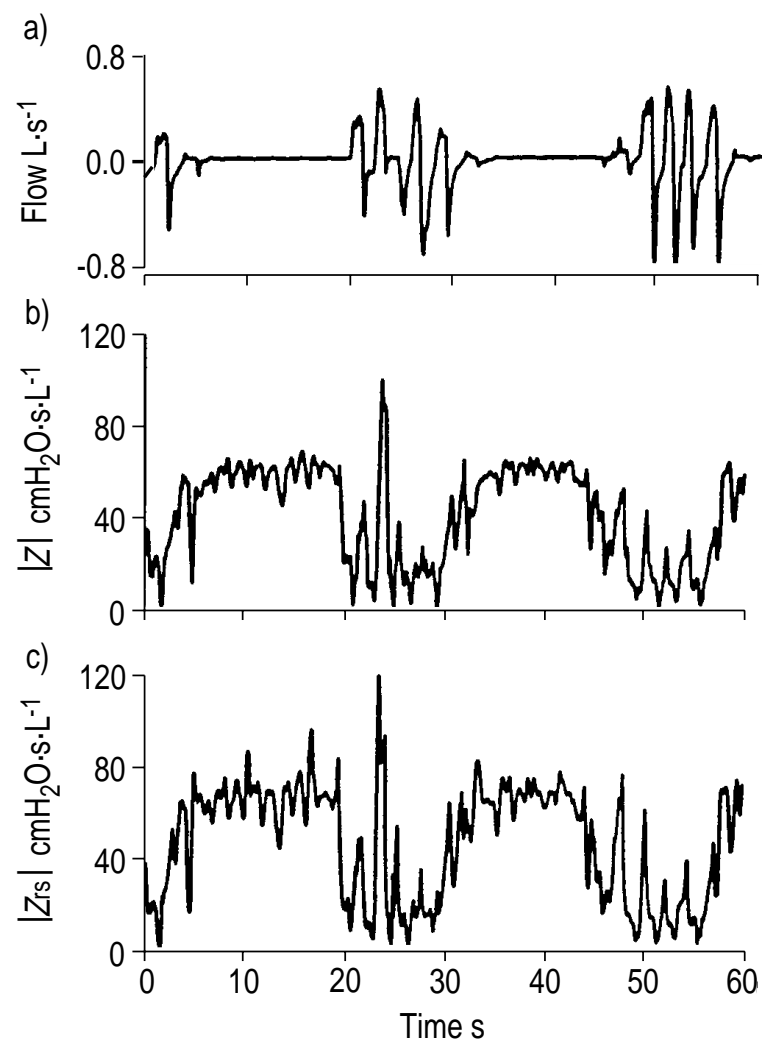

Fig. 2. - Example of a) breathing flow and patient impedance measured with the b) simplified forced oscillation technique (FOT) $(|Z|)$ and actual patient impedance measured simultaneously with c) a reference FOT $\left(\left|Z_{\mathrm{rs}}\right|\right)$ during recurrent obstructive apnoeas. In the figure the $5-\mathrm{Hz}$ oscillation component of the flow signal (positive during inspiration) was filtered out. 

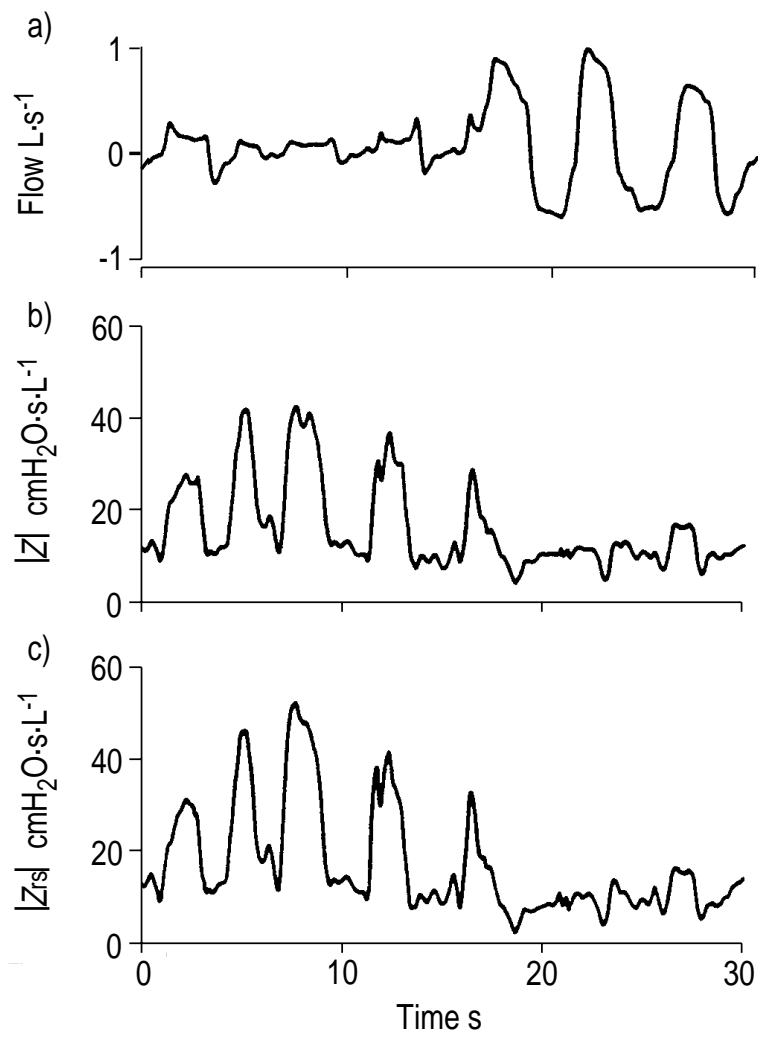

Fig. 3. - Example of a) breathing flow and patient impedance measured with the b) simplified forced oscillation technique (FOT) $(|Z|)$ and actual patient impedance measured simultaneously with c) a reference FOT $\left(\left|Z_{\mathrm{rs}}\right|\right)$ during obstructive hypopnoeas followed by hyperventilation due to arousal. In the figure the $5-\mathrm{Hz}$ oscillation component of the flow signal (positive during inspiration) was filtered out.

dependence with actual impedance $(|Z|-|Z \mathrm{rs}|=1.3$ $\left.\mathrm{cmH}_{2} \mathrm{O} \cdot \mathrm{s} \cdot \mathrm{L}^{-1}-0.16 \times Z \mathrm{rs} ; \mathrm{r}=0.92\right)$. However, the magnitude of this difference could be neglected for clinical applications: the mean difference in impedance values was $-1.4 \mathrm{cmH} \mathrm{H}_{2} \mathrm{O} \cdot \mathrm{s} \cdot \mathrm{L}^{-1}$ and the limits of agreement, defined as mean $\pm 2 \mathrm{sD}$ of the difference, were 3.4 and -6.2 $\mathrm{cmH}_{2} \mathrm{O} \cdot \mathrm{s} \cdot \mathrm{L}^{-1}$.

The results obtained when comparing the capability of $|Z|$ and $|Z \mathrm{rs}|$ for detecting the respiratory events indicated that in all the patients both the simplified FOT and the reference FOT detected the same events as the flow signal. No false positive or negative events were scored by $|Z|$ as compared with $|Z \mathrm{rs}|$. Moreover, both $|Z|$ and $|Z \mathrm{rs}|$ detected the same events of mouth expiration observed by the flow signal (fig. 4).

Figure 6 shows an example to illustrate that nasal flow estimated from measured $V^{\prime}$ reproduced the patient's breathing pattern in detail. Taking all the flow data involved in the $30 \mathrm{~s}$ represented in figure 6 , an excellent correlation was found between actual $\left(V^{\prime} \mathrm{N}\right)$ and estimated $\left(V^{\prime} \mathrm{N}\right.$,est $)$ nasal flows $\left(V^{\prime} \mathrm{N}\right.$,est $=\mathrm{a} \times$ $\left.V^{\prime} \mathrm{N}+\mathrm{b}\right): \mathrm{a}=1.02$ and $\mathrm{b}=0.03 \quad(\mathrm{r}=0.999)$. When this procedure to estimate nasal flow from $V^{\prime}$ was applied to all the patients and CPAP values, it was found that, on the average $( \pm \mathrm{SD}), \mathrm{a}=1.06 \pm 0.03$ and $\mathrm{b}=0.03 \pm 0.03 \mathrm{~L} \cdot \mathrm{s}^{-1}$, with a coefficient of linear correlation $r=0.99$ in all cases.
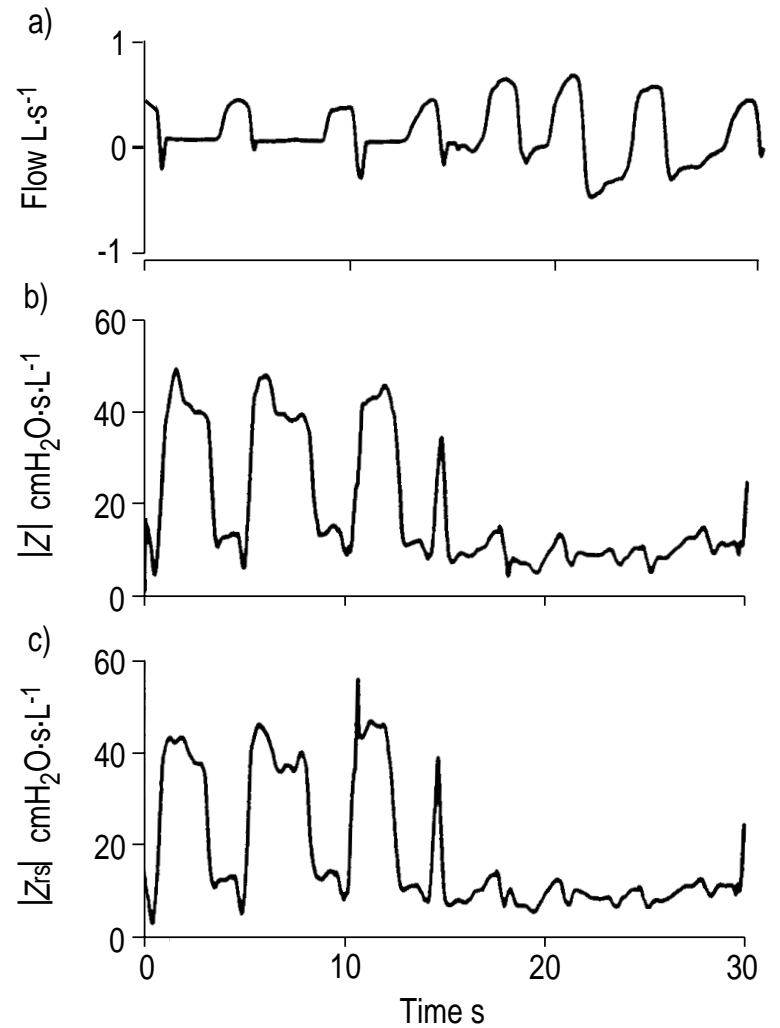

Fig. 4. - Example of a) breathing flow and patient impedance measured with the b) simplified forced oscillation technique (FOT) $(|Z|)$ and actual patient impedance measured simultaneously with c) a reference FOT $\left(\left|Z_{\mathrm{rs}}\right|\right)$ during normal breathing with mouth expiration (nil expiratory nasal flow) followed by normal nasal expiration. In the figure the $5 \mathrm{~Hz}$ oscillation component of the flow signal (positive during inspiration) was filtered out.

\section{Discussion}

The results from this patient study demonstrate that the simplified FOT procedure is as suitable as the reference FOT for monitoring airway obstruction during routine sleep studies in patients with SAHS. Indeed, the slight misestimation found in patient impedance (fig. 5), which is attributed to the simplified hypothesis in the correction procedure [8], did not affect the capacity to detect the respiratory events during sleep. Consequently, this simplified FOT can be a suitable tool for facilitating the use of the technique in clinical protocols aimed at characterizing SAHS [4] or at titrating CPAP [5].

As regards its routine applicability, the main advantage of this simplified FOT is that no transducers are connected to the nasal mask. As the device/patient interface is exactly the same as in the conventional CPAP setting (only the nasal mask with the exhaust port and the tubing) the application of this simplified FOT is extremely easy both for the patient and the sleep technician. In addition to increasing patient comfort, moving the transducers from the nasal mask also avoids potential disconnection of the sensors and the problems induced by secretions and air condensation, especially in the pneumotachograph. From a practical viewpoint, 

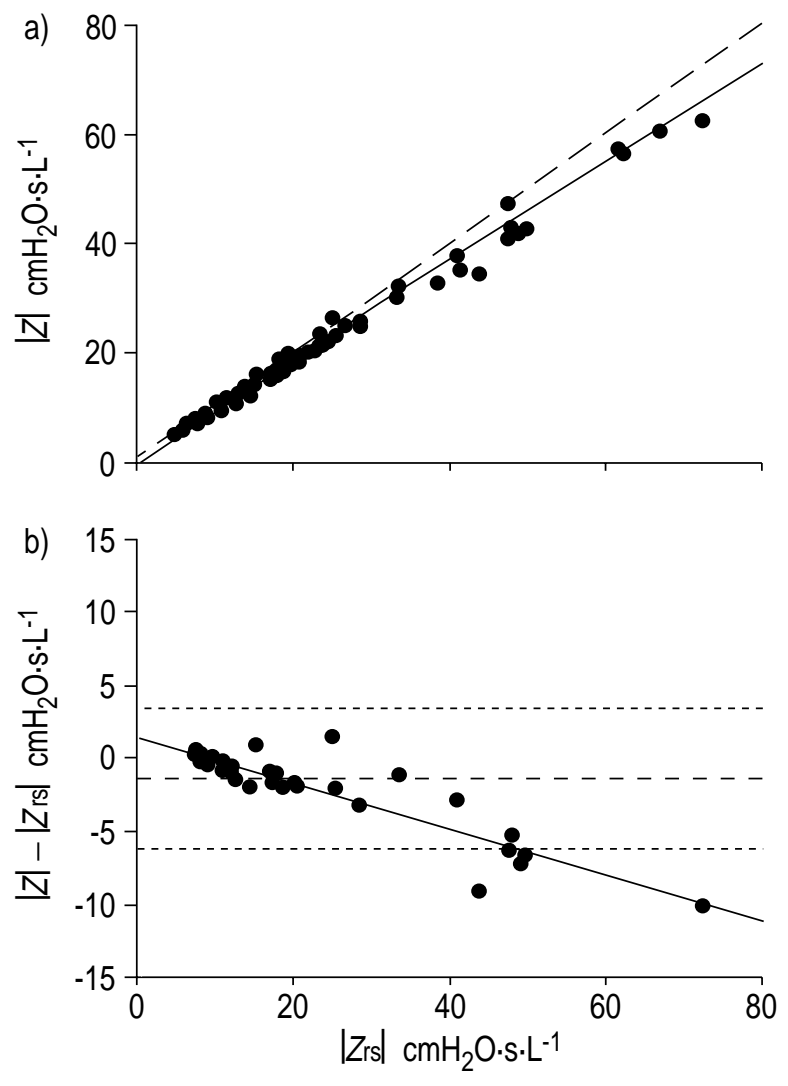

Fig. 5. - a) Patient impedance measured with the simplified forced oscillation technique (FOT) $(|Z|)$ and actual patient impedance measured with a reference FOT $\left(\left|Z_{\mathrm{rs}}\right|\right)$. Data correspond to the highest and lowest values observed in all patients and CPAP. $---:$ the identity line; - : is the regression line. b) Difference $(|Z|-|Z \mathrm{rs}|)$ between estimated and actual impedance as a function of actual value $\left(\left|Z_{\mathrm{rs}}\right|\right)$. — — : mean of the difference; - - - : mean $\pm 2 S D$ of the differences; and - linear regression line.

it is also noteworthy that the calibration procedure of the simplified FOT is easily carried out. The only calibration parameters needed to estimate patient's airway obstruction from measured $P$ and $V^{\prime}(C \mathrm{~T}, \mathrm{~K} 1$ and $\mathrm{K}_{2}$ ) could be determined as soon as the FOT set-up is implemented. This calibration would remain unchanged since it only depends on the type of tubing and exhaust port used. However, it should be mentioned that the calibration procedure based on only three parameters $C_{T}, \mathrm{~K}_{1}$ and $\mathrm{K}_{2}$ is valid provided that the tubing and exhaust port employed in the setting are well described by the model [8].

The data correction procedure applied to account for the effects of the tubing and the exhaust port is necessary to adequately assess airway impedance. The compression in the tubing as well as the leak through the exhaust port induce considerable artefact. Indeed, the shunt impedance due to $\mathrm{CT}$ at $5 \mathrm{~Hz}\left(54 \mathrm{cmH}_{2} \mathrm{O} \cdot \mathrm{s} \cdot \mathrm{L}^{-}\right.$ $\left.{ }^{1}\right)$ and the shunt impedance due to airleak through the exhaust port $\left(40-60 \mathrm{cmH}_{2} \mathrm{O} \cdot \mathrm{s} \cdot \mathrm{L}^{-1}\right.$, depending on the CPAP value) have values which are similar or even lower than patient impedance during the obstructive events (figs. 2-4). Consequently, airway obstruction would be considerably underestimated if no correction was applied. This artefact would be considerable during
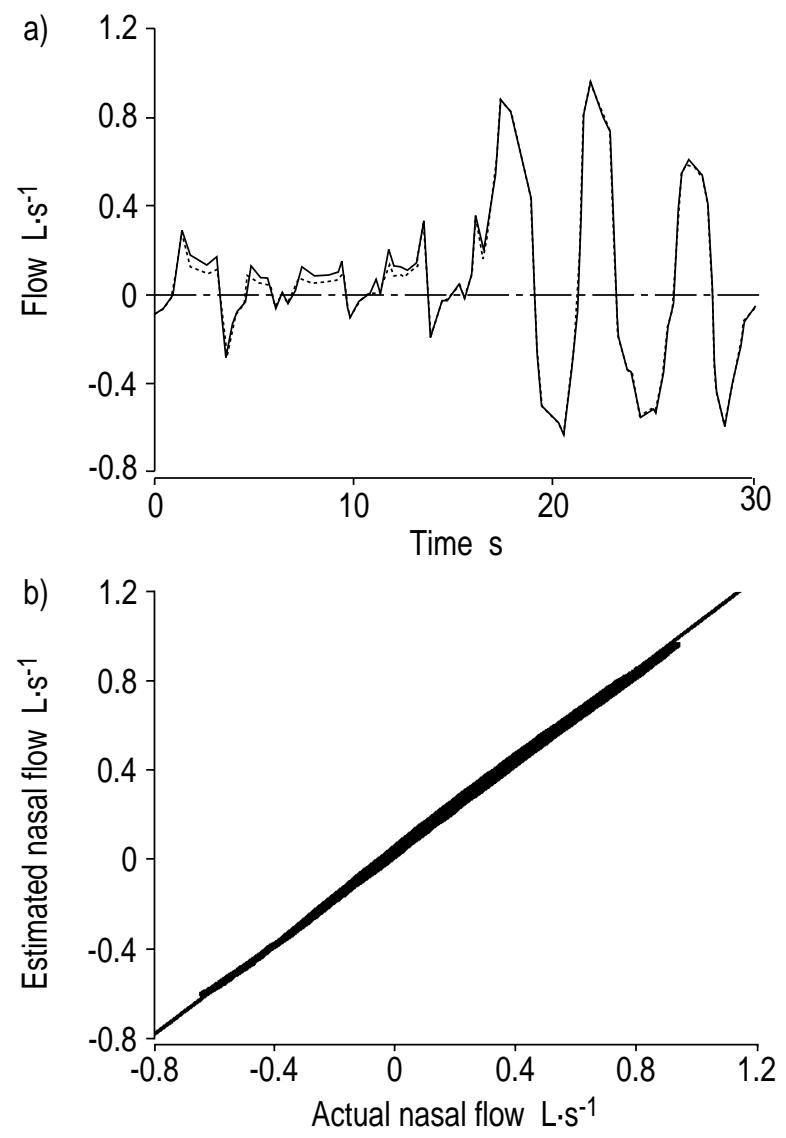

Fig. 6. - a) Flow during and after obstructive hypopnoeas in a patient with sleep apnoea/hypopnoea syndrome (SAHS). $\cdots \cdots$. actual nasal flow (positive during inspiration) measured by a pneumotachograph placed at the entrance of the mask; - : nasal flow estimated from flow $V^{\prime}$ recorded in the forced oscillation technique (FOT) set-up (fig. 1). In the figure the $5-\mathrm{Hz}$ oscillation component was filtered out. b) Estimated versus actual nasal flow. - : linear regression line.

the obstructive events with high impedance characterizing SAHS. In particular, the range of impedance $|Z|$ in the measurements would be reduced from 5.2-61.9 $\mathrm{cmH}_{2} \mathrm{O} \cdot \mathrm{s} \cdot \mathrm{L}^{-1}$ (fig. 5) to only $5.0-21.8 \mathrm{cmH}_{2} \mathrm{O} \cdot \mathrm{s} \cdot \mathrm{L}^{-1}$. This reduction in the impedance range from normal breathing to total airway occlusion is in keeping with the maximum value of $18 \mathrm{cmH}_{2} \mathrm{O} \cdot \mathrm{s} \cdot \mathrm{L}^{-1}$ reported during total airway occlusion when flow was measured at the entrance of the tubing and no correction was applied [9].

Similarly as in another FOT setting where no pneumotachograph is employed [7, 10], the simplified FOT approach avoids the practical drawbacks of placing a pneumotachograph at the nasal mask. However, one advantage of this approach is that it provides an accurate estimation of nasal flow (fig. 6), which is potentially useful to simplify the characterization of the different respiratory events in patients with SAHS from the flow contour curve $[11,13]$. As has been previously reported, using the flow signal during FOT measurements is helpful in avoiding potential misinterpretation of impedance data. Analysing the flow signal allows the detection and quantification of air leak 
through the nasal mask, thereby avoiding the errors due to the associated loss of sensitivity [5]. Moreover, the flow signal is helpful in correctly interpreting impedance changes due to arousals or to mouth expiration. The latter event, which is not uncommon in patients with SAHS [5], results in phasic increases in expiratory impedance (fig. 4). Such impedance changes could be erroneously attributed to obstructive hypopnoeas (fig. 3) if the flow signal was not analysed.

In conclusion, the results obtained in this patient study demonstrate the applicability and reliability of the simplified forced oscillation technique for the routine assessment of airway obstruction during sleep in patients with sleep apnoea/hypopnoea syndrome. As all the instrumentation employed is removed from the patient (fig. 1), the method may be implemented in a compact forced oscillation technique device. To further facilitate its routine applicability, both at the sleep lab and at home, the whole set-up may be optimized by employing a unique device simultaneously generating continuous positive airway pressure and oscillation [14]. Moreover, the implementation of a system for signal processing [15] and for event classification could be particularly suitable for continuously auto adjusting the optimal continuous positive airway pressure.

\section{References}

1. Farré R, Gavela E, Rotger M, Ferrer M, Roca J, Navajas D. Noninvasive assessment of respiratory resistance in severe chronic respiratory patients with nasal CPAP. Eur Respir J 2000; 15: 314-319.

2. Farré R, Peslin R, Rotger M, Navajas D. Inspiratory dynamic obstruction detected by forced oscillation during CPAP. A model Study. Am J Respir Crit Care Med 1997; 155: 952-956.

3. Navajas D, Farré R, Rotger M, Badia R, Puig-deMorales M, Montserrat JM. Assessment of airflow obstruction during CPAP by means of forced oscillation in patients with sleep apnea. Am J Respir Crit Care Med 1998; 157: 1526-1530.

4. Badia JR, Farré R, Montserrat JM, et al. Forced oscillation technique for the evaluation of the sleep apnea hypopnea syndrome. A pilot study. Eur Respir J 1998; 11: 1128-1134.
5. Badia JR, Farré R, Kimoff J, Ballester E, Hernandez L, Rotger M, Navajas D. Clinical application of the forced oscillation technique for CPAP titration in the sleep apnea/hypopnea syndrome. Am J Respir Crit Care Med 1999; 160: 1550-1554.

6. Lorino AM, Lofaso F, Duizabo D, et al. Respiratory resistive impedance as an index of airway obstruction during nasal continuous positive airway titration. $\mathrm{Am}$ J Respir Crit CareMed 1998; 158: 1465-1470.

7. Randerath WJ, Parys K, Felsmeyer F, Sanner B, Rühle KH. Self-adjusting nasal continuous positive airway pressure therapy based on measurement of impedance. Chest 1999; 116: 991-999.

8. Navajas D, Duvivier C, Farré R, Peslin R. A simplified method for monitoring respiratory impedance during continuous positive airway pressure. Eur Respir $J$ 2000; 15: 185-191.

9. Yen FC, Behbehani K, Lucas EA, Burk JR, Axe JR. A noninvasive technique for detecting obstructive and central sleep apnea. IEEE Trans Biomed Eng 1997; 44: 1262-1268.

10. Reisch S, Schneider M, Timmer J, Geiger K, Guttmann J. Evaluation of forced oscillation technique for early detection of airway obstruction in sleep apnea: a model study. Technol Health Care 1998; 6: 245-257.

11. Condos R, Norman RG, Krishnasamy I, Peduzzi N, Goldring RM, Rapoport DM. Flow limitation as a noninvasive assessment of residual upper-airway resistance during continuous positive airway pressure therapy of obstructive sleep apnea. Am J Respir Crit Care Med 1994; 150: 475-480.

12. Montserrat JM, Ballester E, Olivi H, et al. Time course of step-wise CPAP titration. Behavior of respiratory and neurological variables. Am J Respir Crit Care Med 1995; 152: 1854-1859.

13. Ballester E, Badia JR, Hernandez L, Farré R, Navajas $\mathrm{D}$, Montserrat JM. Nasal prongs in the detection of sleep-related disordered breathing in the sleep apnoea/ hypopnoea syndrome. Eur Respir J 1998; 11: 880-883.

14. Farré R, Rotger M, Montserrat JM, Navajas D. A system to generate simultaneous forced oscillation and continuous positive airway pressure. Eur Respir $J$ 1997; 10: 1349-1353.

15. Farré R, Rotger M, Montserrat JM, Navajas D. Ana$\log$ circuit for real-time computation of respiratory mechanical impedance in sleep studies. IEEE Trans Biomed Eng 1997; 44: 1156-1159. 